\title{
Neovascularization and functional recovery after intracerebral hemorrhage is conditioned by the Tp53 Arg72Pro single-nucleotide polymorphism
}

\author{
Cristina Rodríguez ${ }^{1,2}$, Tomás Sobrino ${ }^{3}$, Jesús Agulla ${ }^{1,2}$, Verónica Bobo-Jiménez ${ }^{1,2}$, María E Ramos-Araque ${ }^{1,2}$, Juan J Duarte ${ }^{1}$, \\ José C Gómez-Sánchez ${ }^{1}$, Juan P Bolaños ${ }^{1,2}$, José Castillo ${ }^{3}$ and Ángeles Almeida ${ }^{*, 1,2}$
}

Intracerebral hemorrhage (ICH) is a devastating subtype of stroke that lacks effective therapy and reliable prognosis. Neovascularization following ICH is an essential compensatory response that mediates brain repair and modulates the clinical outcome of stroke patients. However, the mechanism that dictates this process is unknown. Bone marrow-derived endothelial progenitor cells (EPCs) promote endothelial repair and contribute to ischemia-induced neovascularization. The human Tp53 gene harbors a common single-nucleotide polymorphism (SNP) at codon 72, which yields an arginine-to-proline amino-acidic substitution (Arg72Pro) that modulates the apoptotic activity of the p53 protein. Previously, we found that this SNP controls neuronal susceptibility to ischemia-induced apoptosis in vitro. Here, we evaluated the impact of the Tp53 Arg72Pro SNP on vascular repair and functional recovery after ICH. We first analyzed EPC mobilization and functional outcome based on the modified Rankin scale scores in a hospital-based cohort of 78 patients with non-traumatic ICH. Patients harboring the Pro allele of the Tp53 Arg72Pro SNP showed higher levels of circulating EPC-containing CD $34^{+}$cells, EPC-mobilizing cytokines - vascular endothelial growth factor and stromal cell-derived factor- $1 \alpha$ - and good functional outcome following ICH, when compared with the homozygous Arg allele patients, which is compatible with increased neovascularization. To assess directly whether Tp53 Arg72Pro SNP regulated neovascularization after ICH, we used the humanized Tp53 Arg72Pro knock-in mice, which were subjected to the collagenase-induced ICH. The brain endothelial cells of the Pro allele-carrying mice were highly resistant to ICH-mediated apoptosis, which facilitated cytokine-mediated EPC mobilization, cerebrovascular repair and functional recovery. However, these processes were not observed in the Arg allele-carrying mice. These results reveal that the Tp53 Arg72Pro SNP determines neovascularization, brain repair and neurological recovery after ICH. This study is the first in which the Pro allele of Tp53 is linked to vascular repair and ability to functionally recover from stroke.

Cell Death and Differentiation (2017) 24, 144-154; doi:10.1038/cdd.2016.109; published online 21 October 2016

Non-traumatic intracerebral hemorrhage $(\mathrm{ICH})$ is one of the most devastating and disabling forms of stroke that account for $10-15 \%$ of all cases of stroke hospital admissions. ${ }^{1,2,3}$ The average mortality rate was $50 \%$, most of which occur during the first days after stroke. Among survivors, only an estimated $20 \%$ will regain functional independence at 6 months, whereas more than one-third of affected patients will not survive the first year. ${ }^{1,3}$ Unfortunately, prediction of functional outcome that would assist in both preventive and therapeutic interventions remains elusive. ${ }^{1,3}$

Functional outcome after $\mathrm{ICH}$ depends on the balance between brain injury and the activation of yet unknown compensatory response repairing the consequent damage. ${ }^{4,5}$ Recent evidences indicate that strategies to enhance the response following brain injury provide promising opportunities to improve clinical outcomes and brain repair. ${ }^{5}$ Then, to develop effective therapies that promote brain repair, we must have an understanding of the cellular and molecular events involved in the recovery from an ischemic insult.

The adult brain vascular system is stable under normal conditions and is activated in response to pathological conditions including injury. ${ }^{6}$ Neovascularization following stroke is an essential compensatory response mediating brain repair, as it stimulates blood flow and metabolism in the damaged area $^{7,8}$ that activate other brain remodeling poststroke events leading to improved functional outcome of stroke patients. ${ }^{9,10}$ Neovascularization requires new vessel formation from mature endothelial cells and immature CD34 ${ }^{+}$ progenitor cells that includes endothelial progenitor cells (EPCs). These progenitor cells are mobilized from the bone marrow after vascular injury and home to the site of neovascularization, contributing to regeneration by either

${ }^{1}$ Institute of Biomedical Research of Salamanca, University Hospital of Salamanca-University of Salamanca, Salamanca, Spain; ${ }^{2}$ Institute of Functional Biology and Genomics, University of Salamanca-CSIC, Salamanca, Spain and ${ }^{3}$ Health Research Institute of Santiago de Compostela, University Clinical Hospital-University of Santiago de Compostela, A Coruña, Spain

*Corresponding author: A Almeida, Institute of Biomedical Research of Salamanca, University Hospital of Salamanca-University of Salamanca, Calle Zacarías González 2 , Salamanca 37007, Spain. Tel: +34 923 294908; Fax: +34 923 224876; E-mail: aaparra@usal.es

Abbreviations: Ang-1, angiopoietin-1; EPC, endothelial progenitor cell; ICH, intracerebral hemorrhage; IB4, isolectin-B4; mRS, modified Rankin Scale; SNP, singlenucleotide polymorphism; SDF-1 $\alpha$, stromal cell-derived factor-1 $\alpha$; TUNEL, terminal deoxynucleotidyl transferase dUTP nick-end labeling; VEGF, vascular endothelial growth factor; VEGFR2, VEGF receptor-2

Received 02.4.16; revised 29.8.16; accepted 07.9.16; Edited by M Deshmukh; published online 21.10.16 
direct incorporation into newly forming vascular structures or indirectly via the secretion of proangiogenic growth factors, thereby enhancing the overall vascular recovery of ischemic brain. ${ }^{11-14}$ Furthermore, emerging evidences confer to circulating EPC levels a prognostic value in the prediction of functional outcome in ischemic stroke ${ }^{15-17}$ and $\mathrm{ICH}^{18}$ patients.

The human Tp53 gene harbors a common single-nucleotide polymorphism (SNP) at codon 72, which yields an arginine-toproline amino-acidic substitution (Tp53 Arg72Pro SNP) that modulates the apoptotic activity of the tumor suppressor protein p53. ${ }^{19-22}$ Previously, we found that the Tp53 Arg72Pro SNP controls neuronal susceptibility to ischemia-induced apoptosis in vitro. $^{23}$ In this study, we show that the Tp53 Arg72Pro SNP modulates endothelial cell survival after experimental $\mathrm{ICH}$ in vivo, which promotes EPC mobilization and neovascularization. Furthermore, functional recovery of patients after $\mathrm{ICH}$ is conditioned by the Tp53 Arg72Pro genotype. Our results thus reveal a novel function of the Tp53 Arg72Pro SNP in cerebrovascular repair and neurological outcome after stroke.

\section{Results}

The Tp53 Pro allele is associated with high levels of circulating $\mathrm{CD}^{+} 4^{+}$cells and good functional prognosis after ICH. To assess whether the Tp53 Arg72Pro SNP is associated with long-term (12 months) prognosis after $\mathrm{ICH}$, patients (see Table 1 for baseline characteristics) were matched by functional outcome at discharge based on the modified Rankin scale (mRS) scores $^{24}$ (Table 2). We found that homozygous Arg allele patients (referred as Arg patients) with good outcome (mRS $\leqslant 2$ ) at discharge suffered progressive disability $(m R S>2)$ after $\mathrm{ICH}$. In contrast, patients harboring the Pro allele (referred as Pro patients) maintained a favorable outcome, even at long term after ICH (Figure 1a). Moreover, functional recovery was time-dependently improved in the Pro patients who had poor functional outcome $(m R S>2)$ at discharge, whereas it worsened in the Arg patients (Figure 1b). Interestingly, although the lesion volume on admission (Figure 1c) and perihematoma edema volume at 48-72 $\mathrm{h}$ following $\mathrm{ICH}$ (Figure 1d) were similar in both genotypes, indicating similar initial hemorrhagic damage, a fourfold lower residual cavity volume was observed in Pro patients at 6 months after $\mathrm{ICH}$ when compared with Arg patients (Figure 1e). Taken together, these results indicate that Tp53-codon 72 Pro allele-carrying subjects are protected against long-term poor functional outcome after $\mathrm{ICH}$, whereas the homozygous Arg allele is associated to poor prognosis.

To understand the mechanism responsible for the long-term difference in prognosis of both alleles, we focused on neovascularization, a late-onset process that facilitates the neurogenesis, synaptogenesis and synaptic plasticity responsible for the long-term repair of the ischemic brain. ${ }^{9}$ Neovascularization after cerebral ischemia is promoted by circulating CD34 ${ }^{+}$progenitor cells ${ }^{11,13,14,25}$ and, although the mechanism is unknown, it correlates with functional outcome in ischemic stroke ${ }^{15-17}$ and $\mathrm{ICH}^{18}$ patients. We first corroborated this correlation in our $\mathrm{ICH}$ cohort (Figure 2a). Thus,
Table 1 Baseline demographic and clinical features of patients

\begin{tabular}{|c|c|}
\hline Variables & $\mathrm{ICH}(n=78)$ \\
\hline Age (years) & $70.4 \pm 11.1$ \\
\hline \multicolumn{2}{|l|}{ Gender } \\
\hline Females, $n(\%)$ & $24(30.8)$ \\
\hline Males, $n(\%)$ & $54(69.2)$ \\
\hline Time from ICH onset (h) & $5.1 \pm 3.7$ \\
\hline \multicolumn{2}{|l|}{ Diagnosis } \\
\hline \multicolumn{2}{|l|}{ Etiologic } \\
\hline Hypertensive, $n(\%)$ & $36(46.2)$ \\
\hline Amyloid, $n(\%)$ & 26 (33.3) \\
\hline Anticoagulants, $n(\%)$ & $3(3.8)$ \\
\hline Undetermined, $n(\%)$ & $13(16.7)$ \\
\hline \multicolumn{2}{|l|}{ Topographic } \\
\hline Deep, $n(\%)$ & $48(61.5)$ \\
\hline Lobar, $n(\%)$ & $30(38.5)$ \\
\hline Ventricular extension, $n(\%)$ & $23(29.5)$ \\
\hline NIHSS on admission & $10[5,16]$ \\
\hline Lesion volume on admission (ml) & $28.8 \pm 27.9$ \\
\hline Residual lesion volume at 6 months $(\mathrm{ml})$ & $11.7+17.7$ \\
\hline Poor prognosis at 3 months, $n(\%)$ & $42(53.8)$ \\
\hline \multicolumn{2}{|l|}{ mRS at 3 months } \\
\hline $0, n(\%)$ & $10(12.8)$ \\
\hline $1, n(\%)$ & $17(21.8)$ \\
\hline $2, n(\%)$ & $9(11.5)$ \\
\hline $3, n(\%)$ & $12(15.9)$ \\
\hline $4, n(\%)$ & $9(11.5)$ \\
\hline $5, n(\%)$ & $3(3.8)$ \\
\hline $6, n(\%)$ & $18(23.1)$ \\
\hline \multicolumn{2}{|l|}{ Tp53 Arg72Pro SNP } \\
\hline Pro (Arg/Pro+Pro/Pro), $n$ (\%) & $31(39.8)$ \\
\hline $\operatorname{Arg}(\operatorname{Arg} / \operatorname{Arg}), n(\%)$ & $47(60.2)$ \\
\hline \multicolumn{2}{|l|}{ Circulating $C D 34^{+}$progenitor cells } \\
\hline $\begin{array}{l}\text { At admission, cells per } 2.5 \times 10^{5} \text { events } \\
\text { At day } 7 \text {, cells per } 2.5 \times 10^{5} \text { events }\end{array}$ & $\begin{array}{c}203.9 \pm 90.7 \\
359.9 \pm 138.4\end{array}$ \\
\hline
\end{tabular}

Abbreviations: $\mathrm{ICH}$, intracerebral hemorrhage; mRS, modified Rankin Scale; NIHSS, National Institute of Health Stroke Scale; SNP, single-nucleotide polymorphism.

Patients were admitted at the University Hospital of Santiago de Compostela (Galicia, Spain). Data are shown as percentage ( $n, \%)$, mean (S.D.) or medians (quartiles).

levels of circulating $\mathrm{CD} 34^{+}$progenitor increased in patients with good functional outcome, whereas remained unchanged in those with poor prognosis (Figure 2a). To elucidate whether the Tp53 Arg72Pro SNP influenced neovascularization, we next matched patients by genotype and determined the levels of circulating CD34 ${ }^{+}$cells. As shown in Figure $2 \mathrm{~b}$, whilst levels of $\mathrm{CD}_{3} 4^{+}$cells at admission were similar in both genotypes, they significantly increased as soon as 7 days following $\mathrm{ICH}$ in Pro, but not in Arg patients. Interestingly, the patients showing the highest levels of $\mathrm{CD}^{+} 4^{+}$cells at 7 days after $\mathrm{ICH}$ corresponded with the Pro genotype and good prognosis ( $m R \leqslant 2$ at 3 months); in contrast, the patients with the lowest $\mathrm{CD}_{3}{ }^{+}$levels were those of the Arg genotype and poor prognosis (mRS $>2$ at 3 months) (Figure $2 \mathrm{c}$ ). Flow cytometry analysis of the $\mathrm{CD}_{3} 4^{+}$progenitor cells revealed that the observed differences in $\mathrm{CD} 34^{+}$cell levels were not due to cell survival changes (Figure 2d). Next, we analyzed vascular endothelial growth factor (VEGF), angiopoietin-1 (Ang-1) and stromal cell-derived factor-1a (SDF-1a) for their known roles in 
the activation and mobilization of progenitor cells from the bone marrow in response to peripheral tissue hypoxia after stroke, ${ }^{12,26}$ and migration of EPC to injured tissues ${ }^{8,27}$ to promote neovascularization. Serum levels of VEGF (Figure 1e), Ang-1 (Figure 1f) and SDF-1a (Figure 1g) were significantly higher in Pro patients when compared with Arg patients, at $72 \mathrm{~h}$ after $\mathrm{ICH}$. Altogether, these data indicate that the Tp53 Arg72Pro SNP determines the release of progenitor

Table 2 Modified Rankin Scale

\begin{tabular}{|c|c|}
\hline Grade & Criteria \\
\hline 0 & No symptoms at all \\
\hline 1 & $\begin{array}{l}\text { No significant disability: despite symptoms, able to carry } \\
\text { out all usual duties and activities }\end{array}$ \\
\hline 2 & $\begin{array}{l}\text { Slight disability: unable to perform all previous activities } \\
\text { but able to look after own affairs without assistance }\end{array}$ \\
\hline 3 & $\begin{array}{l}\text { Moderate disability: requiring some help but able to walk } \\
\text { without assistance }\end{array}$ \\
\hline 4 & $\begin{array}{l}\text { Moderately severe disability: unable to walk without } \\
\text { assistance and unable to attend to own bodily needs } \\
\text { without assistance }\end{array}$ \\
\hline 5 & $\begin{array}{l}\text { Severe disability: bedridden, incontinent and requiring } \\
\text { constant nursing care and attention }\end{array}$ \\
\hline 6 & Death \\
\hline
\end{tabular}

Modified from Banks and Marotta ${ }^{24}$

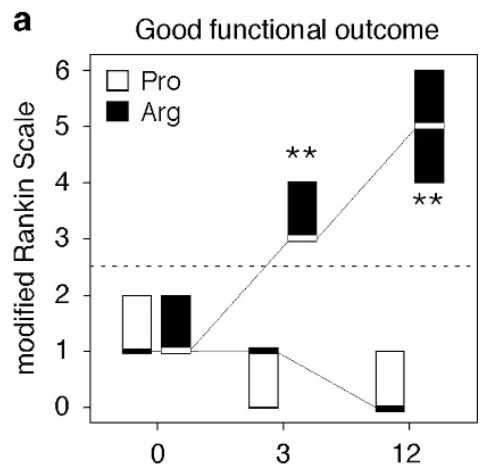

Time after discharge (months)

cell-activating factors and EPC mobilization from the bone marrow as a compensatory response to promote brain repair and functional recovery after $\mathrm{ICH}$ in humans.

The p53 Pro variant increases endothelial cell survival and triggers efficient EPC mobilization via VEGF and SDF-1a leading to neovascularization after experimental ICH. To investigate directly the impact of the Tp53 Arg72Pro SNP on neovascularization after $\mathrm{ICH}$, we next subjected humanized Tp53 knock-in (KI) mice models of both Arg72Pro codon variants ${ }^{28}$ to a previously validated experimental $\mathrm{ICH}^{29}$ As shown in Figures $3 a$ and $b$, the lesion volume observed at $6 \mathrm{~h}$ after experimental $\mathrm{ICH}$ was similar in both genotypes, indicating similar initial hemorrhagic insult; however, the time-dependent decrease in lesion volume was significantly faster in Pro than in Arg allele-carrying mice. Next, we evaluated functional recovery of mice after $\mathrm{ICH}$ by testing motor coordination and limb strength using the accelerated rotarod test. ${ }^{30,31}$ Whereas at $24 \mathrm{~h}$ after $\mathrm{ICH}$ motor impairment was similar in both genotypes, mice expressing the Pro variant showed better motor performance than those with the Arg variant at both $48 \mathrm{~h}$ and 7 days after the hemorrhagic insult, which reflects a different level of functional recovery. Furthermore, mice carrying the Pro allele reached basal (before $\mathrm{ICH}$ ) motor performance at 7 days

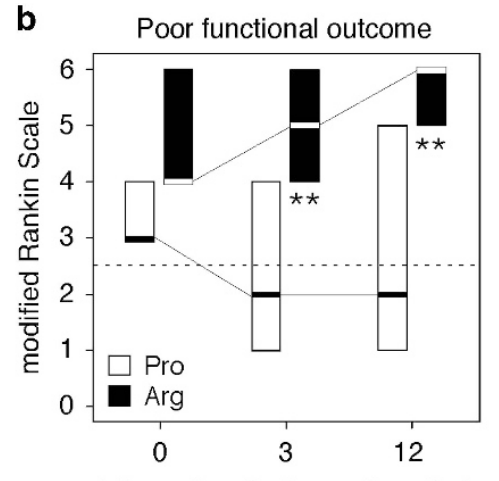

Time after discharge (months)

e

C

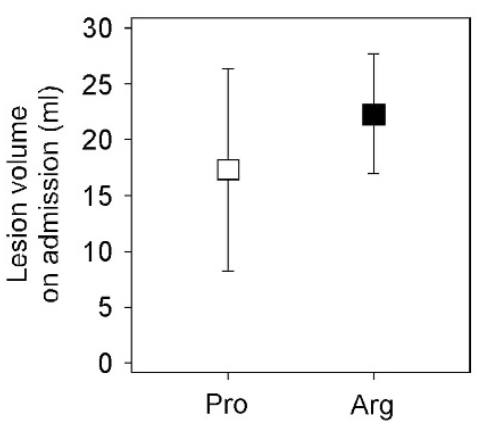

d

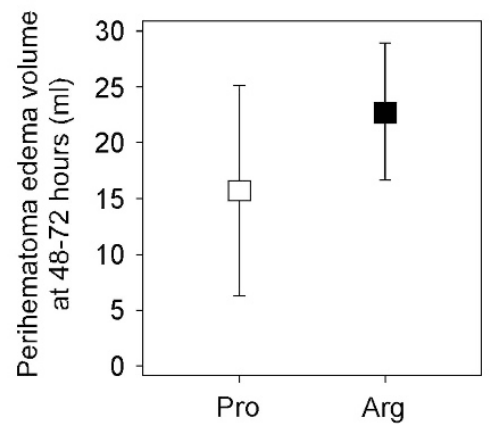

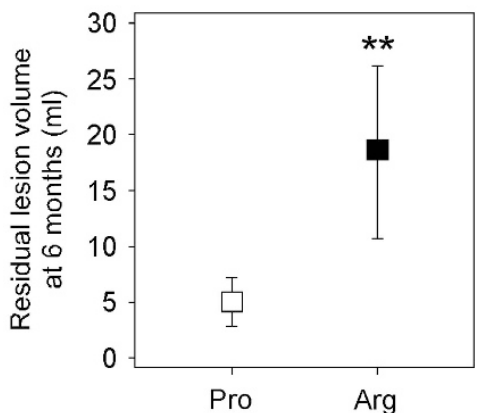

Figure 1 The Tp53 Arg72Pro SNP modulates long-term functional outcome after ICH. Patients were admitted at the University Clinical Hospital of Santiago de Compostela (Galicia, Spain). The study included 78 (Arg/Arg: 47, referred as Arg; Arg/Pro and Pro/Pro: 31, referred as Pro) patients with non-traumatic ICH. (a and b) Modified Rankin Scale (mRS) was used to evaluate the functional outcome of ICH patients. Patients were matched by (a) good (mRS $\leqslant 2$ ) and (b) poor (mRS $>2$ ) functional outcome at discharge and mRS scores were evaluated at 3 and 12 months after ICH with indicated Tp53 Arg72Pro genotypes. Boxplots show median values (horizontal line inside the box) and quartiles (box boundaries) (Mann-Whitney test). (c) Lesion volume on admission, (d) perihematoma edema volume at $48-72 \mathrm{~h}$ after ICH, and (e) residual lesion volume at 6 months after $\mathrm{ICH}$ were measured in patients with indicated Tp53 Arg72Pro genotypes. Data are mean \pm S.D. (Student's t-test). ${ }^{* \star} P<0.0001$ versus Pro patients 


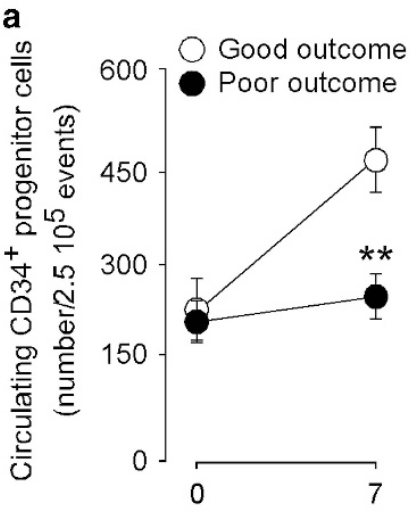

Time after admission (days)

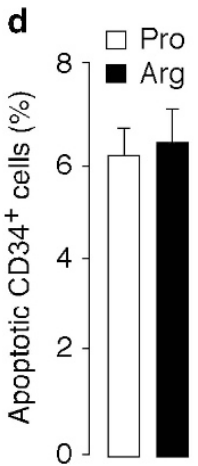

b

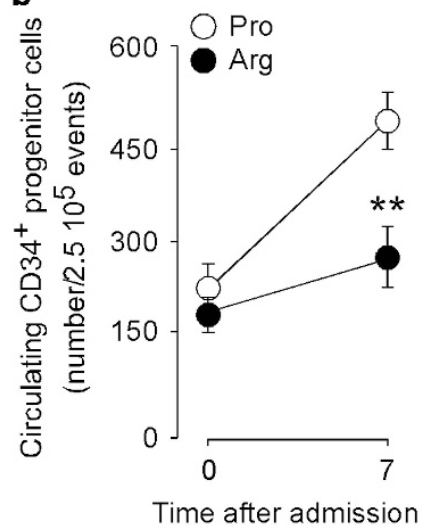

(days)

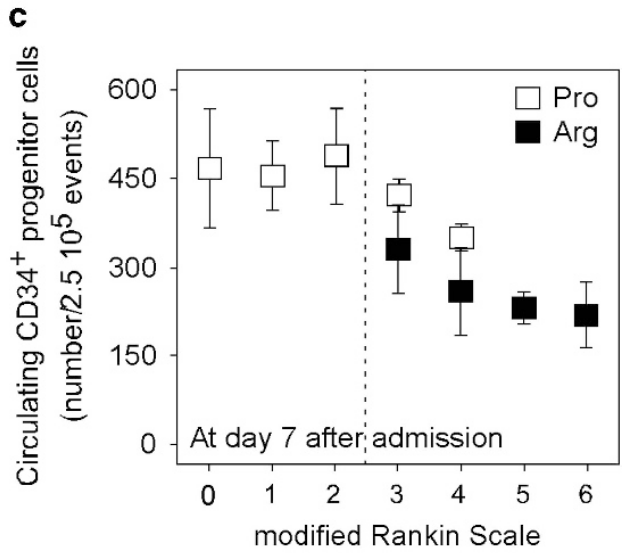

(3 months after $\mathrm{ICH}$ )
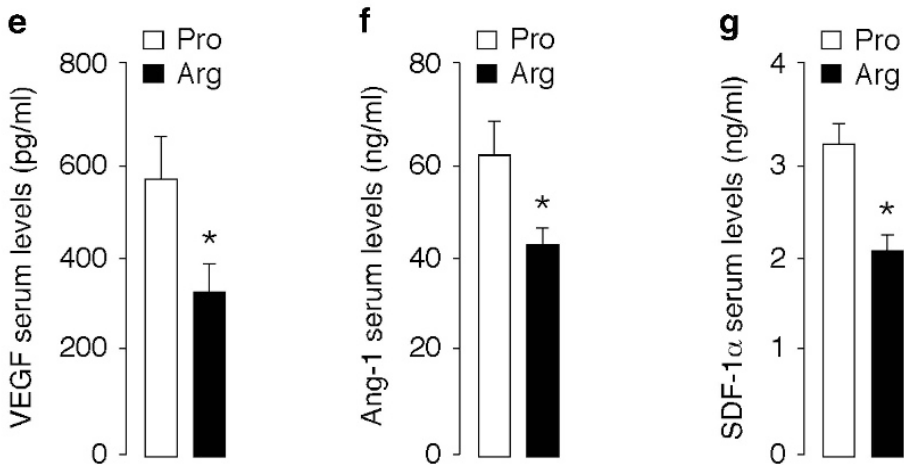

Figure 2 The Tp53 Arg72Pro SNP dictates levels of circulating CD34+ progenitor cells after ICH. Patients were admitted at the University Clinical Hospital of Santiago de Compostela (Galicia, Spain). The study included 78 (Arg/Arg: 47, referred as Arg; Arg/Pro and Pro/Pro: 31, referred as Pro) patients with non-traumatic ICH. (a) Levels of circulating $\mathrm{CD}_{3} 4^{+}$progenitor cells in patients with good (mRS $\leqslant 2 ; 36$ patients) and poor (mRS $>2 ; 42$ patients) functional outcome at 3 months after ICH (one-way analysis of variance (ANOVA) followed by Bonferroni's test). (b) Patients were matched by genotype (Arg and Pro) and we studied circulating levels of CD34 $4^{+}$progenitor cells at 7 days after $\mathrm{ICH}$ in relation to mRS scores at 3 months after ICH. (c) Levels of circulating CD34 $4^{+}$progenitor cells in patients with indicated Tp53 Arg72Pro genotypes (one-way ANOVA followed by Bonferroni's test). (d) Apoptosis (annexin V-APC-stained cells that were 7-AAD-negative) were determined in CD34 ${ }^{+}$progenitor cells by flow cytometry at day 7 following ICH. (g-i) Serum levels of (g) VEGF (pg/ml), (h) Ang-1 (ng/ml) and (i) SDF-1 $\alpha$ (ng/ml) at $72 \mathrm{~h}$ after ICH with indicated Tp53 Arg72Pro genotypes (Student's $t$-test). Data are mean \pm S.D. ${ }^{*} P<0.001 ;{ }^{* \star} P<0.0001$ versus $(\mathbf{a})$ good functional outcome or $(\mathbf{b}-\mathbf{g})$ Pro patients

after $\mathrm{ICH}$; however, this effect was not observed in the Arg allele-carrying mice (Figure $3 c$ ), indicating poorer functional recovery than the Pro mice. All these findings confirm the results observed in humans (Figure 1), supporting that the humanized Tp53 Arg72Pro SNP KI mice variants functionally recapitulate the human phenotypes.

In vivo terminal deoxynucleotidyl transferase dUTP nickend labeling (TUNEL) staining revealed significantly less apoptotic cell death in the perihematoma area in the mice harboring the Pro allele than in those with the Arg allele (Figure 3d). Among the affected cells, we found not only neurons ( $\mathrm{TUNEL}^{+} \mathrm{NeuN}^{+}$cells) (Figure 3e) but also endothelial cells (TUNEL ${ }^{+} \mathrm{CD}_{3}{ }^{+}$cells) (Figure 3f), which both underwent less apoptotic death in the Pro mice than in the Arg one. In vitro ischemia (oxygen and glucose deprivation) confirmed higher survival of cultured brain endothelial cells obtained from the Pro mice (Figure $3 \mathrm{~g}$ ). We therefore hypothesized whether endothelial cells' survival against $\mathrm{ICH}$ dictated the production and release of angiogenic and EPCmobilizing factors, including VEGF, Ang-1 and SDF-1 $a$ that led to the EPC mobilization, cerebrovascular repair and functional prognosis observed in patients (Figures 1a and 2e-g). To test this, we measured circulating levels of $\mathrm{CD} 34^{+}$progenitor cells in both the Tp53 Pro and Arg SNP variant KI mice after experimental $\mathrm{ICH}$. In good agreement with the data observed in $\mathrm{ICH}$ patients (Figure $2 \mathrm{~b}$ ), the levels of $\mathrm{CD} 34^{+}$progenitor cells were significantly higher in the Pro mice when compared with the Arg one, $24 \mathrm{~h}$ after the insult (Figure $4 \mathrm{a}$ ). Given that CD34 is not exclusively present in EPC, but also on mature endothelial cells - although at a lower level - specific EPC identification should be demonstrated by showing the presence of the endothelial marker VEGF receptor-2 (VEGFR2) and the absence of the pan-leukocyte marker CD45. ${ }^{12,16,32,33}$ We therefore analyzed $\mathrm{CD} 34^{+} / \mathrm{NEGFR}^{+} / \mathrm{CD} 45^{-}$cells by FACS as a bona fide marker of EPC. As shown in Figure $4 b$, experimental $\mathrm{ICH}$ in the Tp53 Arg72Pro mice triggered a $\mathrm{t}$ ime-dependent increase in the circulating levels of EPC in the Pro allele-carrying mice, reaching the maximum level at $24 \mathrm{~h}$ after the insult; however, this effect was significantly attenuated in mice with the Arg allele (Figure 4b). Such difference was not because of a putative differential rate of EPC proliferation at the light of their same BrdU 
incorporation rate (Figure 4c) and cell cycle phase distribution (Figure 4d) in both genotypes. Furthermore, levels of EPC-mobilizing cytokines, VEGF (Figure 4e) and SDF-1a (Figure 4f), sharply increased in the Pro mice after the $\mathrm{ICH}$ insult, whereas this effect was significantly weakened in the Arg mice. Altogether, these results strongly suggest that the regulation of EPC mobilization by these cytokines dictates the different functional outcomes of the Tp53 Pro and Arg alleles in mice and patients after $\mathrm{ICH}$.

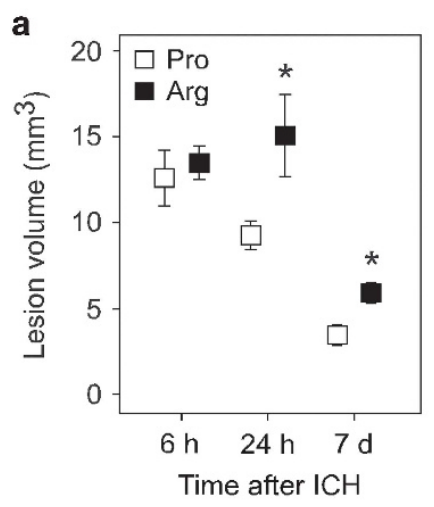

d

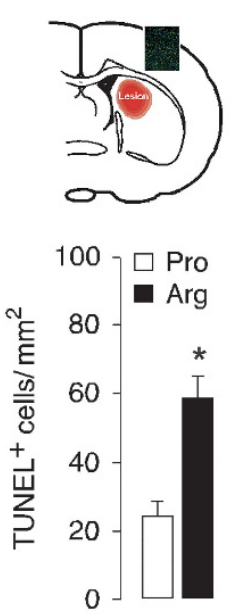

b

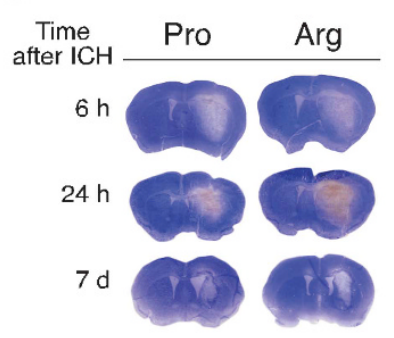

c

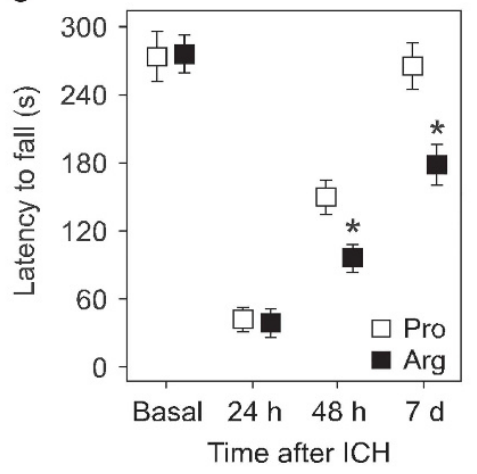

NeUN/TUNEL/DAPI
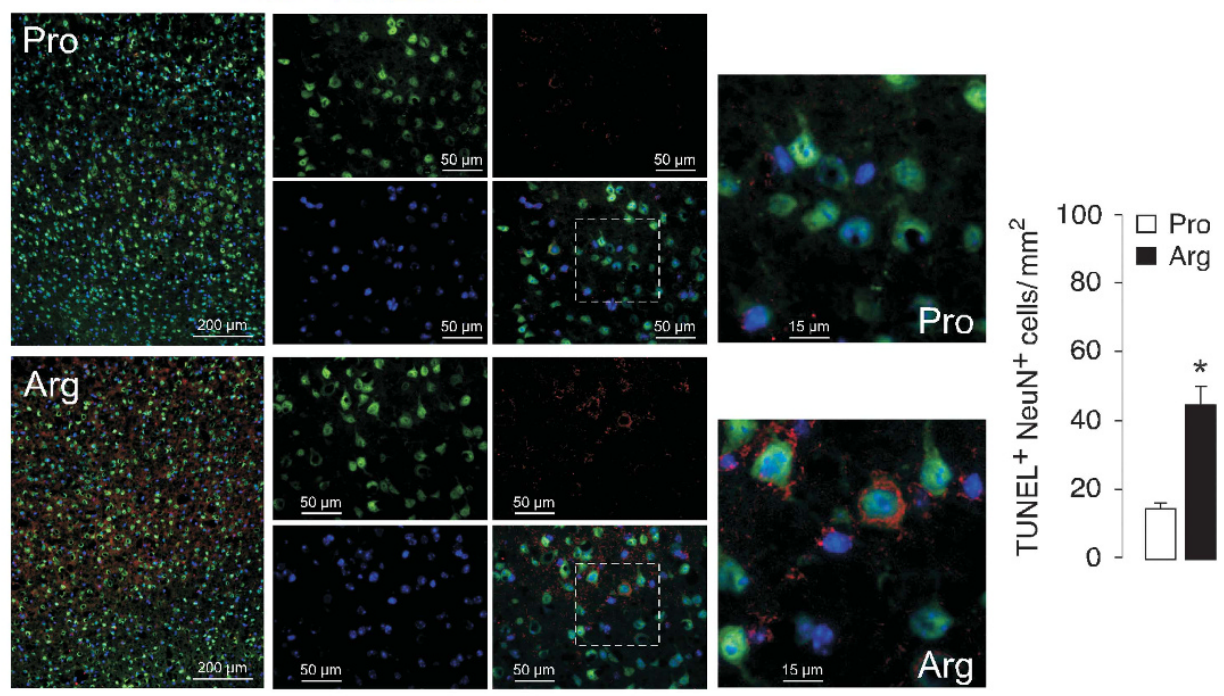

f

CD31/TUNEL/DAPI
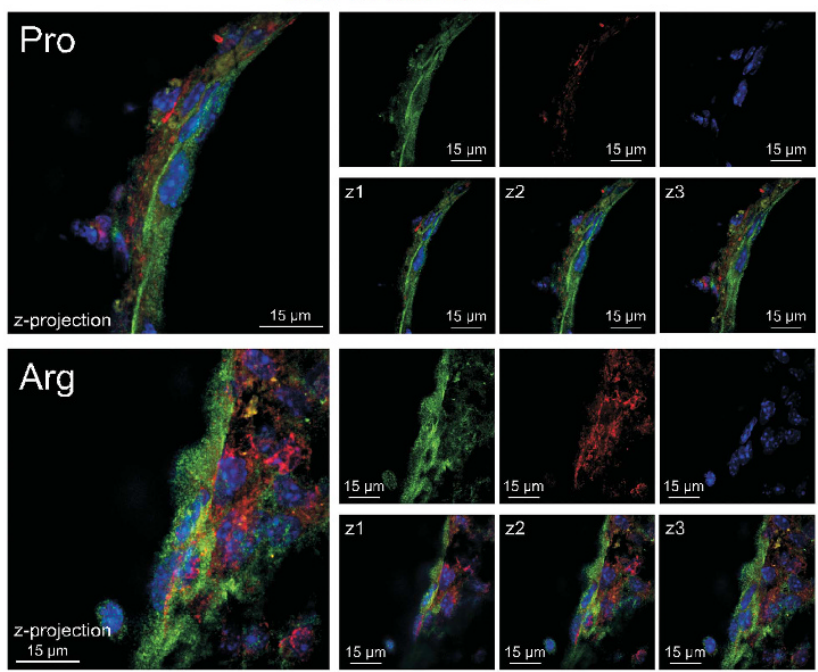

g Brain endothelial cells in primary culture

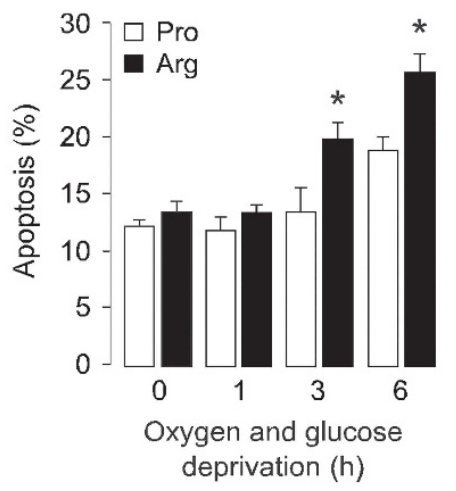




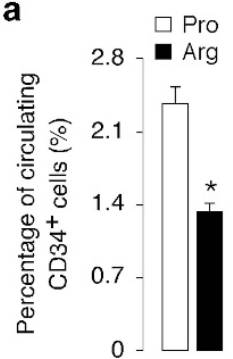

b
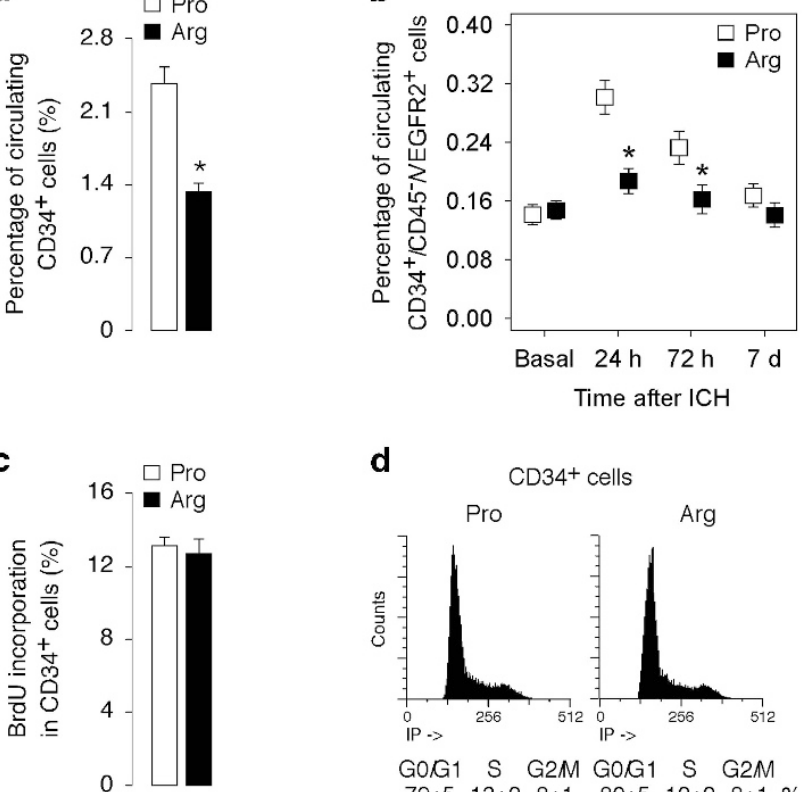

d

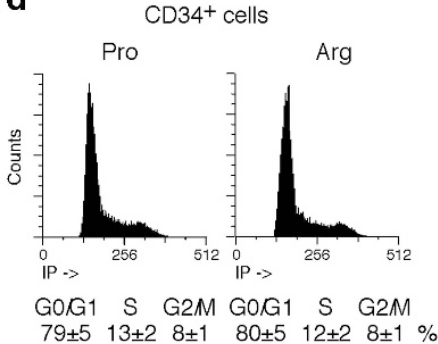

e
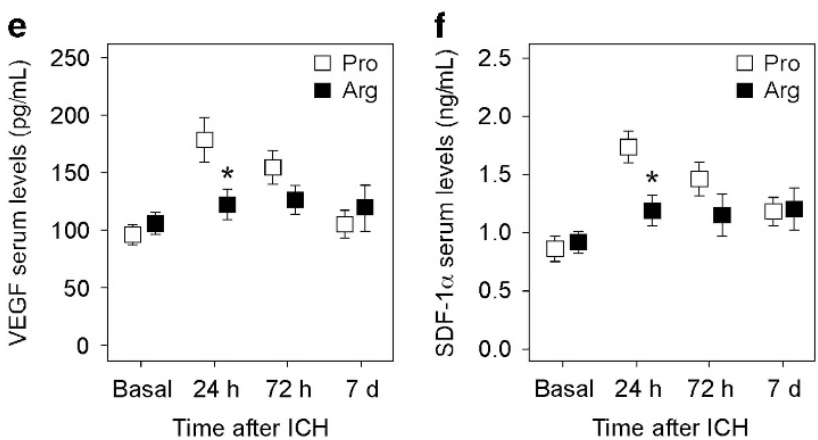

Figure 4 The Pro SNP variant promotes efficient EPC mobilization via VEGF and SDF-1 $\alpha$ following ICH. Humanized knock-in mouse model for both codon Arg72Pro variants of p53 (Pro and Arg) were subjected to experimental ICH. (a) Levels of circulating $\mathrm{CD} 34^{+}$progenitor cells were determined by flow cytometry at $24 \mathrm{~h}$ after experimental ICH. Data are mean \pm S.E.M. (Student's $t$-test; $n=3$ mice per group). (b) Levels of circulating $\mathrm{CD} 34^{+} / \mathrm{CD} 45^{-} / \mathrm{VEGFR2} 2^{+}$cells were determined by flow cytometry at indicated time points after $\mathrm{ICH}$. (c and d) $\mathrm{CD} 34^{+}$cells obtained from bone marrow of Pro and Arg mice were incubated during $3 \mathrm{~h}$ with BrdU $(1 \mathrm{mM})$. (c) BrdU incorporation and (d) cell cycle distribution were determined by flow cytometry. Data are mean \pm S.E.M. ( $n=3$ mice per group). Serum levels of (e) VEGF (pg/ml) and (f) SDF-1 $\alpha(\mathrm{ng} / \mathrm{ml})$ were measured at different time points after ICH (basal: $24 \mathrm{~h}$ before ICH). Data are mean \pm S.E.M. (one-way analysis of variance (ANOVA) followed by Bonferroni's test; $n=4-6$ mice per group). ${ }^{*} P<0.05$ versus Pro
As the ability of healthy endothelial to produce VEGF and SDF-1a has been estimated to be several weeks after the ischemic injury, ${ }^{7}$ it is conceivable to propose that the high survival rate of endothelial cells in the Pro allele herein described is a key factor determining long-lasting production of growth factors and EPC mobilization after $\mathrm{ICH}$. To ascertain whether the Tp53 Arg72Pro SNP determined cerebral neovascularization after $\mathrm{ICH}$, brain sections of the $\mathrm{KI}$ mice were stained with the vascular endothelial cell marker isolectin-B4 (IB4), a well-known index of vascularization. ${ }^{34}$ As IB4 also labels microglial cells, ${ }^{34}$ we first used a combination of IB4 with the microglia-specific marker, Iba1. As shown in Figure $5 \mathrm{a}$, we found microglial cells (IB4 ${ }^{+} / \mathrm{lba}^{+}$cells) in the perihematoma area in both Pro and Arg mice; however, microglia appears to locate around vessels in mice carrying the Pro allele, but not in those with the Arg one (Figure 5b), which may contribute to remove cell debris ${ }^{10,35}$ and promote vascular repair. ${ }^{36}$ In relation to morphology, we found that endothelial cells (IB4 ${ }^{+} / \mathrm{lba} 1^{-}$cells) form tubular structures, whereas microglia (IB4 ${ }^{+} / \mathrm{Iba}^{+}$cells) exhibited a dendritic morphology in both Arg and Pro mice (Figure 5). Furthermore, IB4 staining is more pronounced in endothelial cells (Figure 5a). Therefore, IB4 labeling easily allows distinguishing microglial cells from endothelial cells, hence representing a suitable index of neovascularization as described previously. ${ }^{34}$

We observed that experimental $\mathrm{ICH}$ induced a decrease in IB4 staining in the perihematoma area, $24 \mathrm{~h}$ after the insult in both Pro and Arg allele-carrying mice, suggesting brain blood vessel disruption with endothelial cell loss (Figure 6a). However, this effect was more pronounced in the Arg mice, in good agreement with the higher apoptotic endothelial cell death observed in this genotype (Figure 6a). Interestingly, the vascular density increased in the Pro mice 7 days after $\mathrm{ICH}$, as revealed by the enhanced IB4 staining indicating vascular repair; however, this effect was significantly attenuated in the Arg mice (Figure 6a). We confirmed these observations using the endothelial cell marker, CD31 (Figure 6b). Neovascularization in the Pro allele-carrying mice was further confirmed as judged by the new IB4 ${ }^{+} / \mathrm{Iba1}^{-}$small vessels sprouting ${ }^{34}$ from the existing vasculature (Figure 7). Our results thus demonstrate that vascular repair after $\mathrm{ICH}$ is mainly restricted to the Pro allele-carrying Tp53 Arg72Pro SNP.

\section{Discussion}

During the recovery of the ischemic brain, oxygen and nutrient supply restoration is a critical process that requires the

Figure 3 The Pro SNP variant promotes survival of cerebral endothelial cells and functional recovery following ICH. Humanized knock-in mouse model for both codon Arg72Pro variants of p53 (Pro and Arg) were subjected to experimental ICH. (a) Lesion volume ( $\mathrm{mm}^{3}$ ) was measured on Nissl-stained histological sections from whole brain at indicated time points (one-way analysis of variance (ANOVA) followed by Bonferroni's test; $n=4-5$ mice per group). (b) Representative images of Nissl-stained histological sections from whole brain at indicated time points after ICH. (c) Rotarod testing was performed in mice before (basal) and at indicated time points after ICH. Latency to fall off the rotarod was recorded (one-way ANOVA followed by Bonferroni's test; $n=4-5$ mice per group). (d) Cell apoptosis were determined in the perihematoma brain region by TUNEL assay. Apoptotic cells were quantified as TUNEL (red)-positive cells per $\mathrm{mm}^{2}$ at $24 \mathrm{~h}$ following ICH (Student's $t$-test; $n=4-5$ mice per group). (e) Neuronal apoptosis were identified in perihematoma brain region by double staining with TUNEL (red) and neuronal marker NeuN (green) at $24 \mathrm{~h}$ after ICH (Student's $t$-test; $n=4-5 \mathrm{mice}$ per group). Representative images are shown. (f) Apoptotic endothelial cells were identified in perihematoma brain region by double staining with TUNEL (red) and endothelial cell marker CD31 (green) at $24 \mathrm{~h}$ after ICH. (g) Brain endothelial cells in primary culture were exposed to oxygen and glucose deprivation during 1, 3 and $6 \mathrm{~h}$, and apoptosis were determined by flow cytometry (one-way ANOVA followed by Bonferroni's test; $n=3$ cell cultures per condition). Data are mean \pm S.E.M. ${ }^{*} P<0.05$ versus Pro 
a
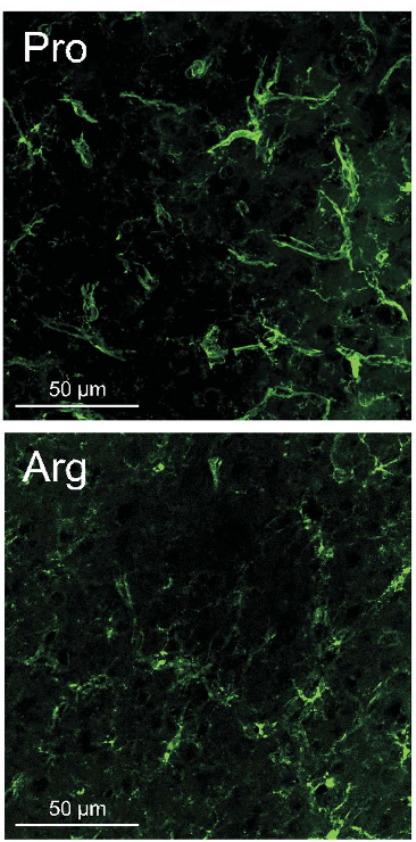

Iba1
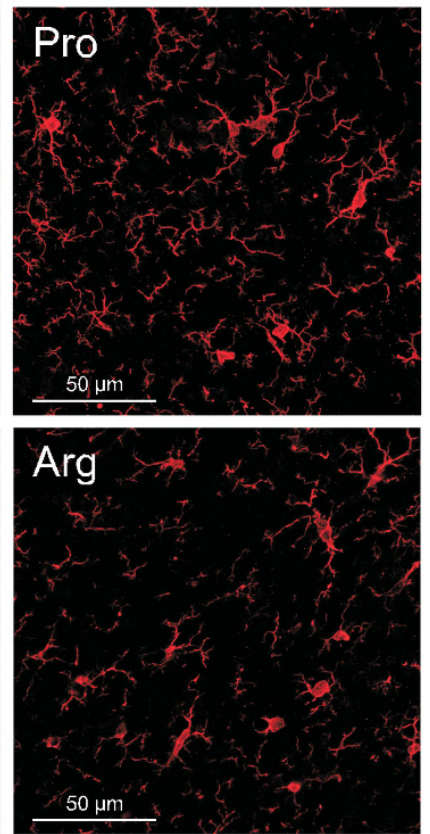

IB4/lba1
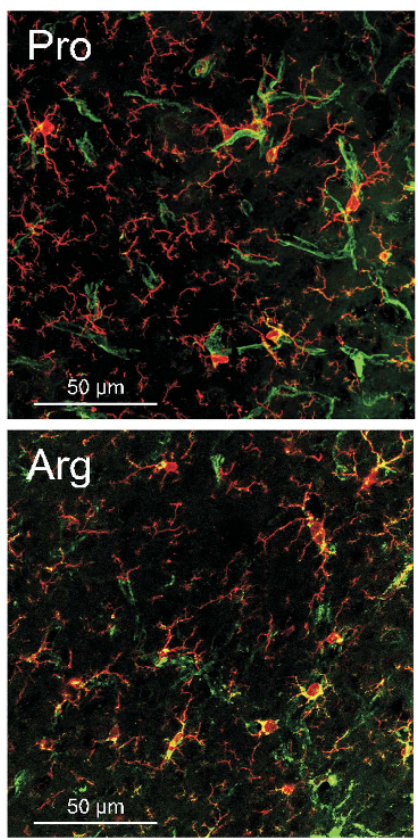

b
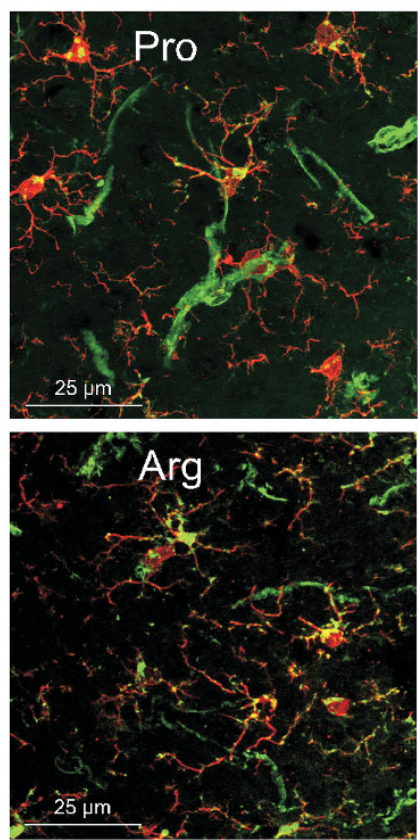

Figure 5 The Pro SNP variant promotes microglia localization around vessels after ICH. (a and b) Humanized knock-in mouse model for both codon Arg72Pro variants of p53 (Pro and Arg) were subjected to experimental ICH. Brain sections were costained with the vascular endothelial cell marker IB4 and the microglia-specific marker Iba1 at day 7 after experimental ICH. Nuclei were stained with the far-red fluorescent specific DNA dye TO-PRO3

neovascularization of the affected area, where it stimulates the blood flow and metabolism ${ }^{7,8}$ to induce poststroke brain remodeling and improved functional outcome. ${ }^{9,10}$ In this study, we describe that the Tp53 Arg72Pro SNP dictates functional prognosis after $\mathrm{ICH}$ through a mechanism that involves endogenous bone marrow-derived EPC mobilization leading to neovascularization.

Delayed revascularization of postischemic brain tissue is known to be the main obstacle to preserve the brain function in stroke and ischemic retinopathies. ${ }^{37,38}$ Here, we found that the patients harboring the Arg allele show delayed neovascularization, and poor functional outcome after $\mathrm{ICH}$, when compared with the Pro allele carriers. Neovascularization not only augments cerebral flow, ${ }^{7,8}$ but also migration of macrophages to the ischemic area to rapidly remove the necrotic debris. ${ }^{10,35}$ Consequently, the increase in the number of newly formed vessels correlates with long-term survival of stroke patients. ${ }^{10}$ Noticeably, our data show that the Pro allele is associated with increased neovascularization and good longterm functional outcome and survival after $\mathrm{ICH}$.

Progenitor cell mobilization from the bone marrow occurs via the production and release of angiogenic factors, such as VEGF and Ang-1, in response to the peripheral tissue hypoxia after stroke. ${ }^{12,26}$ Moreover, VEGF and the chemokine SDF-1a promote the migration and homing of EPC to the injured tissues, favor EPC differentiation and activate mature endothelial cells during neovascularization.,27 The higher levels of VEGF and SDF-1a, which we found after ICH in Pro allele-carrying patients, thus reflects an efficient mobilization and recruitment of $\mathrm{CD} 34^{+}$progenitor cells - including EPC from the bone marrow to the sites of vascular injury. Besides its direct contribution to the formation of new vessels, recruited progenitor cells to the ischemic brain tissue may also remain in the interstitial space, whereby secreting cytokines and growth factors - for example, SDF-1 $a$ and VEGF - indirectly promote vascular repair via paracrine mechanisms. ${ }^{12,26}$ In addition, it has been described that SDF-1a, released from infarcted brain tissue, together with EPC, operates as a chemotactic factor for the recruitment of additional EPC.,39 Our data are therefore consistent with the notion that this pathway is stimulated in the Pro allele patients leading to improved vascular repair, brain recovery and good functional prognosis after $\mathrm{ICH}$.

To understand the mechanism responsible for the different postischemic neovascularization in Arg and Pro alleles, we focused on our previous data showing that the Tp53 Arg72Pro SNP modulates neuronal survival after ischemia in vitro, ${ }^{23}$ which we now confirm in vivo (this work). Interestingly, besides neurons, the reduced vulnerability to $\mathrm{ICH}$-induced apoptosis is also observed in the endothelial cells of Pro allele patients. Accordingly, healthier endothelial cells, such as those of the Pro patients, will likely produce more VEGF and SDF-1a for longer periods after ischemic injury as shown previously, ${ }^{7}$ hence improving neovascularization. As the long-term prediction of functional outcome has remained elusive, ${ }^{2}$ our results shed light on the long-term survival determinants of $\mathrm{ICH}$ patients.

In conclusion, here we show that different prognosis after $\mathrm{ICH}$ is dictated by the Tp53 Arg72Pro SNP through a mechanism that involves endogenous bone marrow-derived EPC mobilization leading to neovascularization, brain repair and improved functional prognosis after stroke. This study is the first in which the Pro allele of Tp53 is linked to 
a

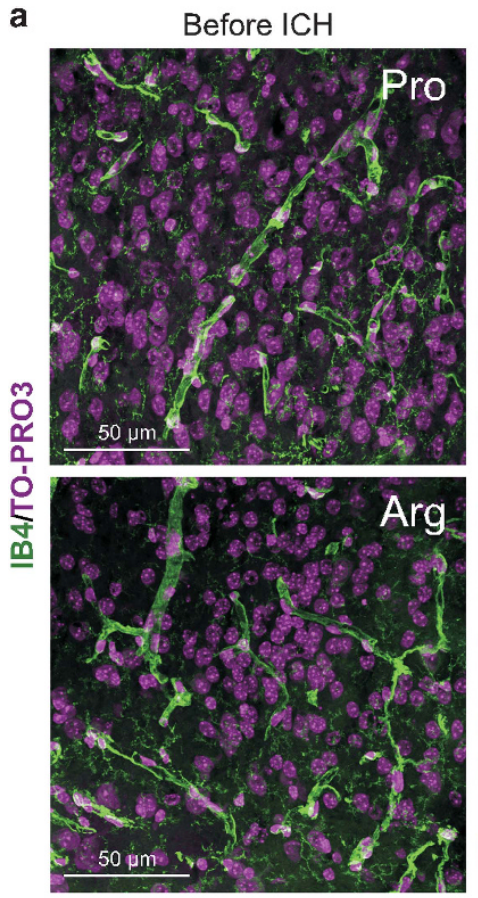

$24 \mathrm{~h}$ after $\mathrm{ICH}$
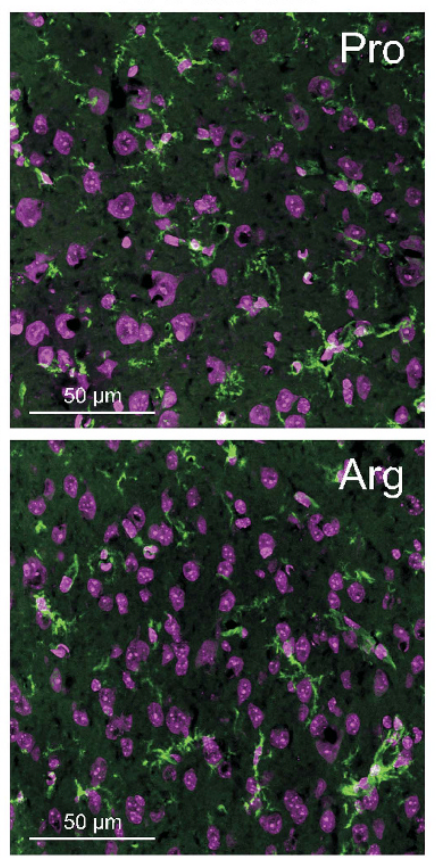

$7 \mathrm{~d}$ after $\mathrm{ICH}$
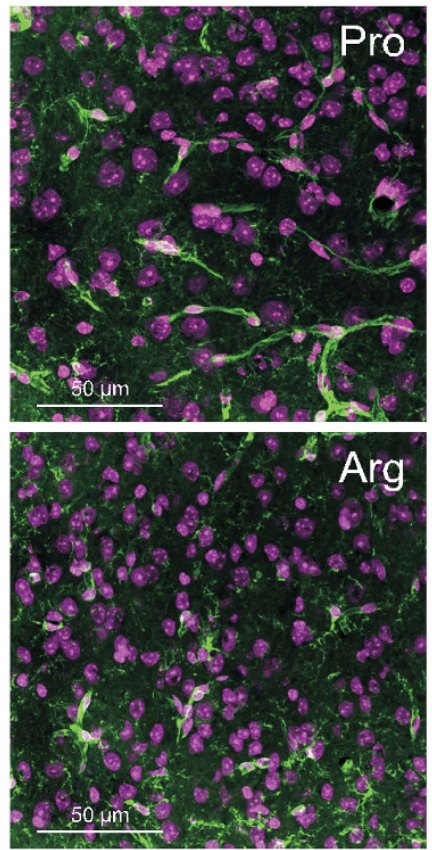

b
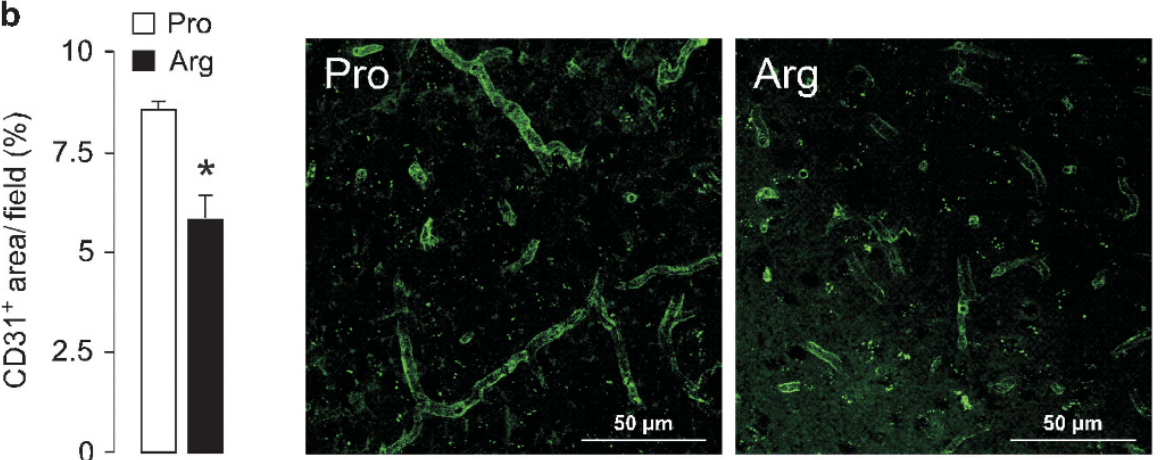

Figure 6 Neovascularization after ICH is conditioned by the Tp53 Arg72Pro SNP. Humanized knock-in mouse model for both codon Arg72Pro variants of p53 (Pro and Arg) were subjected to experimental ICH. (a) Brain sections were stained with the vascular endothelial cell marker IB4 and the far-red fluorescent nuclear dye TO-PRO3 before and after $24 \mathrm{~h}$ and 7 days after ICH. (b) Brain sections were stained with the vascular endothelial cell marker CD31 at day 7 following experimental ICH. Green (CD31) fluorescence area per field was determined using the NIH ImageJ version 1.48 software (NIH, Bethesda, MD, USA). Data are mean \pm S.E.M. (Student's $t$-test; $n=4$ mice per group). ${ }^{*} P<0.05$ versus Pro

angiogenesis and ability to recover functionally from stroke. Thus, we propose that the Tp53 Arg72Pro SNP analysis should be used for the stratification of patients in clinical trials aimed to predict the functional prognosis after $\mathrm{ICH}$. Furthermore, whether the mechanism herein described is also involved in the prognosis of other pathological conditions, such as cancer or chronic inflammation including retinopathies, is a likely possibility deserving further investigation. Therapies aimed to enhance the levels of cytokine-mediated EPC mobilization leading to neovascularization may be considered to improve the functional prognosis of $\mathrm{Arg}$-allelecarrying $\mathrm{ICH}$ patients.

\section{Material and Methods}

Patients. Ninety-six consecutive patients with a first-ever primary non-traumatic $\mathrm{ICH}$ of $<12 \mathrm{~h}$ from symptoms onset and previously independent for their daily living activities were prospectively included in the study between March 2011 and February 2013. Patients with previously altered functional capacity $(m R S \geqslant 1$ ) $(n=4)$, chronic inflammatory diseases $(n=3)$, severe hepatic $(n=3)$ or renal $(n=2)$ diseases, cancer $(n=2)$ or infectious disease in the 15 days before inclusion $(n=1)$ were excluded. Furthermore, three patients did not accept their participation in the study, thus a total of 78 patients (male, 69.2\%; mean age, $70.4 \pm 11.1$ years) were finally included in the study.

This research was carried out in accordance with the Declaration of Helsinki of the World Medical Association (2008) and approved by the Ethics Committee of the Servizo Galego de Saúde. Informed consent was obtained from each patient or their relatives after full explanation of the procedures.

All patients were admitted to an acute stroke unit and treated according to the guidelines of the Cerebrovascular Diseases Study Group of the Spanish Society of Neurology. ${ }^{40}$ Etiological diagnosis was made according the Guidelines for the management of spontaneous ICH in adults from the American Heart Association/ American Stroke Association Stroke Council, High Blood Pressure Research Council and the Quality of Care and Outcomes in Research Interdisciplinary Working Group. ${ }^{41}$ Medical history recording potential vascular risk factors, blood and 
IB4

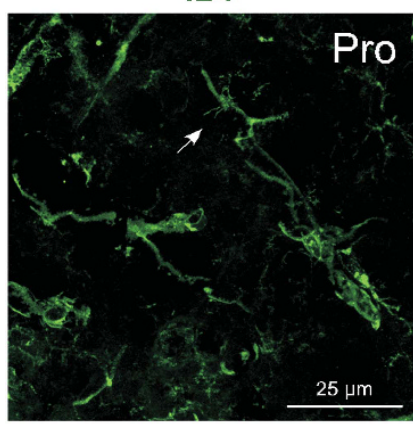

TO-PRO3

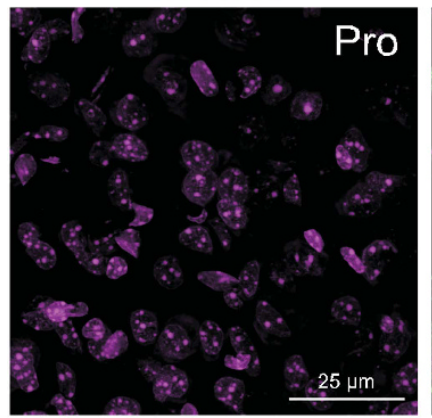

Iba1

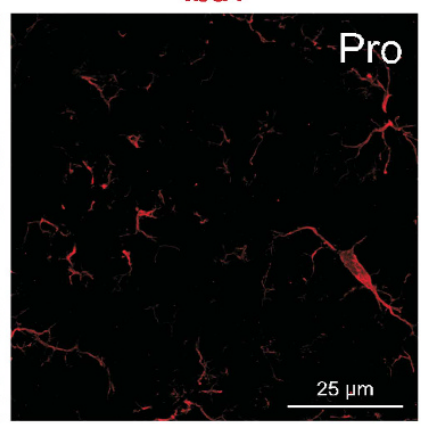

IB4/TO-PRO3

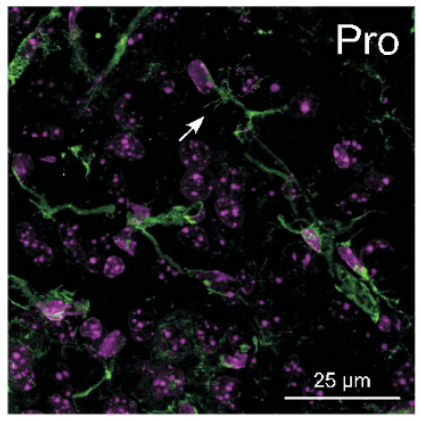

IB4/lba1

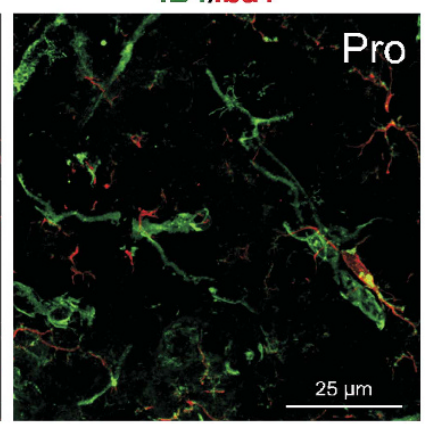

IB4//ba1/TO-PRO3

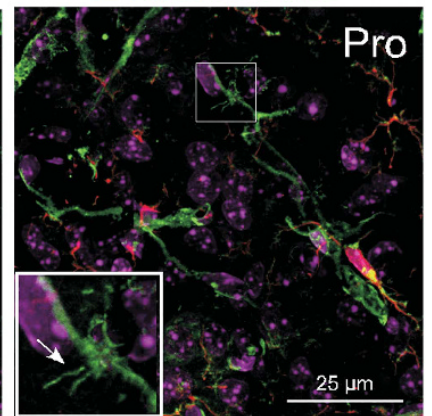

Figure 7 The Pro SNP variant promotes vessel formation after ICH. Humanized knock-in mouse model carrying the Pro SNP variant of p53 were subjected to experimental $\mathrm{ICH}$. Brain sections were costained with the vascular endothelial cell marker IB4 and the microglia-specific marker lba1 at day 7 after experimental ICH. Nuclei were stained with the far-red fluorescent specific DNA dye TO-PRO3. White arrow indicates newly formed vessels

coagulation tests, 12-lead ECG and chest radiography were performed at admission To evaluate neurologic deficit, the National Institute of Health Stroke Scale (NIHSS) was performed at admission. Functional outcome was evaluated at discharge and at 3 and 12 months by using the mRS. NIHSS and mRS were evaluated by internationally certified neurologists. ${ }^{23,24}$ The main outcome variable for all patients was considered poor functional prognosis (mRS $>2$ ) at 3 months \pm 15 days.

Antihypertensive treatment with intravenous labetalol or urapidil was administered in case of systolic blood pressure $>185 \mathrm{~mm} \mathrm{Hg}$ or diastolic blood pressure $>105 \mathrm{~mm} \mathrm{Hg}$. Low-dose subcutaneous heparin was used for the prevention of deep vein thrombosis and pulmonary thromboembolism.

Neuroimaging studies. Lesion volumes of the intracerebral hemorrhagic patients were determined by computed tomography (CT) scan using the formula $0.5 \times a \times b \times c$, where $a$ and $b$ represent the largest perpendicular diameters, and $c$ represents the slice thickness. The hematoma volume was determined upon admission, and the perihematoma edema volume (total volume minus hematoma volume) in a second CT performed after 48-72 $\mathrm{h}$. The residual cavity volume was determined with CT at 6 months \pm 15 days. ICH topography was classified as lobar when it mainly affected the cortical or subcortical white matter of the cerebral lobes or as deep when it was limited to the internal capsule, the basal ganglia or thalamus. The presence of ventricular extension of the hematoma was also recorded. All neuroimaging evaluations were performed by neuroradiologists blinded to the patients' clinical and laboratory results.

Human Tp53 polymorphism analysis. Genotyping of human Tp53 polymorphism was performed at the University of Salamanca by authors blinded to the clinical status of patients, by using the PCR-RFLP technique. ${ }^{23}$ The Tp53 SNP of exon 4 at codon 72 (Arg72Pro; rs1042522) was detected by amplifying genomic DNA with the forward primer $5^{\prime}$-TCTACAGTCCCCCTTGCCGT-3' and the reverse primer 5'-CTGACCGTGCAAGTCACAGA-3'. Tp53 exon 4, where BstU1 (Bsh1236I) RFLP is located, was amplified within a 298-bp DNA fragment. Digests were separated on agarose gel $(3 \%)$ and the Midori Green Advanced-stained DNA fragments (Nippon Genetics Europe GmbH, Düren, Germany) were analyzed under a UV source (Gel Imager System; Bio-Rad, Hercules, CA, USA). The distribution of genotype frequencies in Arg72Pro between the $\mathrm{ICH}$ cohort was within the Hardy-Weinberg equilibrium ( $P>0.1$ in all cases). As the Pro allele is likely to exert a dominant effect on the Arg one, ${ }^{23}$ two groups were considered for this study: Pro (Pro/Pro and Pro/Arg genotypes) and Arg (Arg/Arg genotype) patients.

Animals. The humanized Tp53 Arg72Pro KI mice were generously donated by Prof. DG Johnson (The University of Texas MD Anderson Cancer Center, Smithville, TX, USA). ${ }^{28}$ Animals were bred at the Animal Experimentation Service of the University of Salamanca, in accordance with Spanish legislation (RD 53/2013). Protocols were approved by the Bioethics Committee of the Institute of Biomedical Research of Salamanca. All efforts were made to minimize the number of animals used and ensure minimal suffering. All studies described below were conducted in a blind manner.

Experimental model of ICH. Experimental ICH was induced in 12-week-old mice by injecting bacterial collagenase VII from Clostridium histolyticum (purified by chromatography; Sigma, Madrid, Spain) into the basal ganglia. ${ }^{29}$ Briefly, male mice under sevoflurane anesthesia ( $4 \%$ for induction and $3 \%$ for maintenance) evaporated in an oxygen-air mixture (30-70\%) were placed in a stereotaxic frame (model no. 1900; Kopf, Tujunga, CA, USA) with a digital coordinate readout system (Wizard 550 Readouts; Anilam, Schaumburg, IL, USA). Collagenase ( $0.1 \mathrm{U}$ in $0.5 \mu \mathrm{l}$ of saline) was injected unilaterally into the striatum using stereotactic coordinates: $+0.9 \mathrm{~mm}$ anterior and $+2.0 \mathrm{~mm}$ lateral to bregma, to a depth of $3.5 \mathrm{~mm}$ and at a rate of $0.1 \mu \mathrm{l} / \mathrm{min}$ over $5 \mathrm{~min}$. The needle stayed in place for additional $10 \mathrm{~min}$ to prevent reflux. During the procedure, rectal temperature was monitored (BAT-12 thermometer; Physitemp, Clifton, NJ, USA) and maintained at $37 \pm 0.5^{\circ} \mathrm{C}$. After the surgery, the animals were placed in a warm environment for recovering. Lesion volume was calculated from serial Nissl-stained sections of the mouse brains at $6 \mathrm{~h}$ and 1, 7 and 14 days after collagenase injection.

Accelerated rotarod test. Performance based on motor coordination and limb strength in this test was assessed before (basal) and after $\mathrm{ICH}$. Mice were trained for 3 days before $\mathrm{ICH}$. All determinations were carried out at the same time every testing session by a researcher blind to the genotype. Mice were allowed to 
stay for $300 \mathrm{~s}$ on a five-lane accelerating rotarod (Model 47600; Ugo Basile, Comerio, Italy) rotating rod with a continuous accelerating rotation speed from 4 to 40 r.p.m., increasing 4 r.p.m. every $30 \mathrm{~s}$ and reaching the final speed at $270 \mathrm{~s}$. The latency to fall off the rotarod was measured during this period, annotating the time the animal stayed on the rotation rod. Data from tests in which animals completed three turns without walking were disregarded. ${ }^{42}$

Flow cytometry analysis of circulating progenitor cell levels. A $7 \mathrm{ml}$ sample of EDTA venous blood was obtained from ICH patients at admission and day $7 \pm 1$. Samples were processed within $1 \mathrm{~h}$ after collection by one researcher who had no knowledge of the patients' clinical and radiological results. Mononuclear cells were isolated from peripheral blood by Ficoll density gradient centrifugation suspended in $100 \mathrm{ml}$ of PBS. Immunofluorescence cell staining was performed in triplicate with the fluorescent conjugated antibody CD34-Fluorescein isothiocyanate (FITC; Becton Dickinson, Bergen, NJ, USA). IgG1-FITC antibody (Becton Dickinson) served as a negative control. Fluorescence was measured immediately after staining by flow cytometry (BD FACSAria llu Becton Dickinson). Number of human $\mathrm{CD} 34^{+}$progenitor cells was expressed as absolute cell counts obtained after the measurement of $2.5 \times 10^{5}$ events in the lymphocyte gate (FACS Diva software; BD Biosciences, Bergen, NJ, USA). ${ }^{18}$ In some experiments, following CD34-FITC staining, cells were stained with annexin V-allophycocyanin (APC) and 7-aminoactinomycin D (7-AAD) in binding buffer (100 mM HEPES, $140 \mathrm{mM} \mathrm{NaCl}$ and $2.5 \mathrm{mM} \mathrm{CaCl}_{2}$ ). $\mathrm{CD} 34^{+}$progenitor cells (identified by FITC fluorescence) were analyzed, and the annexin V-APC-stained cells that were 7-AAD-negative were considered to be apoptotic. ${ }^{23,43}$

In the Arg72Pro p53 KI mice, blood samples were collected in EDTA-coated microtainer tubes (Becton Dickinson) at $24 \mathrm{~h}$ before surgery (basal) and at different time points following experimental ICH. Immunofluorescence cell staining was performed in triplicate with the fluorescent conjugated antibodies CD34-FITC, VEGFR2-APC (eBioscience, San Diego, CA, USA) and CD45-phycoerythrin (PE; Immunostep, Salamanca, Spain). Cell fluorescence was measured immediately after staining by flow cytometry. ${ }^{12}$ Percentage of $\mathrm{CD} 34^{+} / \mathrm{NEGFR2}^{+} / \mathrm{CD} 45^{-}$cells was calculated using the CellQuest software (BD Biosciences).

Measurement of VEGF, Ang-1 and SDF-1a serum levels. Blood samples were obtained from ICH patients at $72 \pm 24 \mathrm{~h}$ following $\mathrm{ICH}$, and from Arg72Pro p53 KI mice at different time points after collagenase injection. Samples were centrifuged at $3000 \times \mathrm{g}$ for $10 \mathrm{~min}$ and immediately frozen and stored at $-80^{\circ} \mathrm{C}$. Serum levels of VEGF, Ang- 1 and SDF- $1 \alpha$ were measured using commercially available quantitative ELISA (enzyme-linked immunosorbent assay) Kits (VEGF and Ang-1 (R\&D Systems Inc, Minneapolis, MN, USA) and SDF-1 $\alpha$ (RayBiotech Inc., Norcross, GA, USA and Abcam, Cambridge, UK)). ${ }^{18}$ Intra- and interassay coefficients were $<8 \%$ for all markers.

Cell cultures and treatments. Primary cultures of mouse brain capillary endothelial cell were prepared from cerebral cortices of 3-week-old Arg72Pro p53 $\mathrm{KI}$ mice. ${ }^{44}$ Cortices were isolated, chopped in Dulbecco's modified Eagle's medium (DMEM), and homogenized with a serological pipette. Homogenates were cleaned from myelin using a $20 \%$ (w/v) BSA in DMEM and separated from erythrocytes by two centrifugations at $1000 \times \mathrm{g}$, for $15 \mathrm{~min}$. The resulting suspension was digested in $0.02 \mathrm{mg} / \mathrm{ml}$ collagenase/dispase (Roche, Heidelberg, Germany) in DMEM supplemented with $0.04 \mathrm{mg} / \mathrm{ml} \mathrm{DNase}$ I (Roche), for $1 \mathrm{~h}$ at $37^{\circ} \mathrm{C}$ in a shaking water bath. Cells were seeded on plastic plates coated with collagen I (BD Biosciences) and incubated in endothelial cell growth medium MV2 (Ready-to-use; Promocell, Birmingham, UK) supplemented with L-glutamine (Lonza, Barcelona, Spain) and $3 \mu \mathrm{g} / \mathrm{ml}$ puromycin (Sigma). Brain endothelial cells were exposed to oxygen and glucose deprivation ${ }^{45}$ and were stained with annexin V-APC and 7-AAD in binding buffer to determine quantitatively the percentage of apoptotic cells $\left(\mathrm{V}-\mathrm{APC}^{+} / 7\right.$ $A A D^{-}$) by flow cytometry. 23,43

For isolation of bone marrow progenitor cells from Arg72Pro p53 KI mice, whole bone marrow was collected from bilateral femurs and passed through a $40 \mu \mathrm{m}$ cell strainer (BD Falcon, BD Biosciences). Cells were then seeded on fibronectincoated plates and cultured in RPMI-1640 medium (Sigma) supplemented with 10\% (v/v) FBS. Cells were stained with CD34-FITC and BrdU incorporation and cell cycle phase distribution analysis were performed by flow cytometry, using the APC BrdU Flow Kit (BD Biosciences). BrdU ${ }^{+}$cells and cell cycle distribution was measured immediately after staining in the $\mathrm{CD} 34^{+}$cell population, by flow cytometry. ${ }^{43}$
Immunohistochemistry. Arg72Pro p53 KI mice were anesthetized by intraperitoneal injection of a mixture (1:4) of xilacine hydrochloride (Bayer; Leverkusen, Germany) and ketamine hydrochloride/chlorbutol (Merial; Lyon, France), using $1 \mathrm{ml}$ of the mixture per $\mathrm{kg}$ of body weight, and then perfused intra-aortically with $0.9 \% \mathrm{NaCl}$, followed by $5 \mathrm{ml} / \mathrm{g}$ per body weight of Somogy's fixative (4\% p/v paraformaldehyde, $0.2 \% \mathrm{p} / \mathrm{v}$ picric acid in $0.1 \mathrm{M}$ phosphate buffer, $\mathrm{pH}$ 7.4). After perfusion, brains were dissected out coronally in three parts and postfixed, using the Somogy's fixative, for overnight at $4^{\circ} \mathrm{C}$. Brain blocks were rinsed with $0.1 \mathrm{M}$ phosphate buffer and sequentially immersed in 10\%, $20 \%$ and $30 \%(\mathrm{w} / \mathrm{v})$ sucrose in phosphate buffer until they sank. After cryoprotection, $20-\mu \mathrm{m}$ thick coronal sections were obtained with a freezing-sliding cryostate (Leica CM 1950 AgProtect; Leica Microsystems, Wetzlar, Germany). Coronal sections were rinsed in $0.1 \mathrm{M} \mathrm{PB}$ three times each for $10 \mathrm{~min}$ and then incubated in (i) $1: 250$ anti-mouse CD31 (550274; BD Pharmingen, BD Biosciences), 1: 200 anti-lba1 (019-19741; Wako, Chemicals, Neuss, Germany), 1: 1000 anti-NeuN (MAB377; Merck Millipore, Bellerica, MA, USA) or 1:50 anti-IB4 (L2140; Sigma) in $0.2 \%$ Triton X-100 (Sigma) and 5\% goat serum (Jackson Immoresearch Laboratories, West Grove, PA, USA) for $72 \mathrm{~h}$ at $4{ }^{\circ} \mathrm{C}$ in $0.1 \mathrm{M} \mathrm{PB}$; (ii) fluorophore-conjugated secondary antibodies (Jackson Immunoresearch Laboratories) in $0.05 \%$ Triton $\mathrm{X}-100$ and $2 \%$ goat serum in $0.1 \mathrm{M}$ phosphate buffer, for $2 \mathrm{~h}$ at room temperature. ${ }^{42}$ Nuclei were stained either with 6-diamidino-2-phenylindole (DAPI, blue fluorescence; Sigma D9542) or the commercial monomeric cyanine nucleic acid stain TO-PRO3 (far-red fluorescence; Molecular Probes T3605, Invitrogen) for $10 \mathrm{~min}$. After rinsing with PBS, sections were mounted with Fluoromount (Sigma) aqueous mounting medium. Sections were examined with epifluorescence and appropriated filters sets using a microscope (Nikon Inverted microscope Eclipse Ti-E; Nikon, Tokyo, Japan) equipped with a precentered fiber illuminator (Nikon Intensilight C-HGFI, Tokyo, Japan) and B/W CCD digital camera (Hamamatsu; Tokyo, Japan), or with a spectral laser confocal microscope (Leica TSC-SL; Leica Microsystems) with three lasers: multiline Argon ( $488 \mathrm{~nm})$, Helium-Neon $(543 \mathrm{~nm})$ and HeliumNeon $(633 \mathrm{~nm})$, and equipped with $\times 40, \times 63$ (1.4) HCX PL Apo oil immersion objectives for high-resolution imaging. Quantifications were performed in three regions of interest from three different sections per animal in an epifluorescence/ light microscope (Nikon, Tokyo, Japan). Area occupied by $\mathrm{CD} 31^{+}$vessels was estimated by using the NIH image-processing package ImageJ (ImageJ 1.48v).

TUNEL assay. TUNEL assay was performed in brain sections following the manufacturer's protocol (Roche Diagnostics, Heidelberg, Germany). Brain sections, fixed as above, were preincubated in TUNEL buffer containing $1 \mathrm{mM} \mathrm{CoCl}$, $140 \mathrm{mM}$ sodium cacodylate and $0.3 \%$ Triton X-100 in $30 \mathrm{mM}$ Tris buffer, $\mathrm{pH} 7.2$, for $30 \mathrm{~min}$. After incubation at $37^{\circ} \mathrm{C}$ with the TUNEL reaction mixture containing terminal deoxynucleotidyl transferase $(800 / \mathrm{ml})$ and nucleotide mixture $(1 \mu \mathrm{M})$ for 90 min, sections were rinsed with PBS and counterstained with Cy3-streptavidin (Jackson Immunoresearch Laboratories). ${ }^{42}$

Statistics. Clinical results are expressed as either the mean \pm S.D. or median (25th and 75th percentiles) for the continuous variables depending on whether or not the data followed a normal distribution, respectively. The Kolmogorov-Smirnov test was used for testing the normality of the distribution. The Student's $t$-test (normal data) or the Mann-Whitney test (non-normal data) was used to compare continuous variables between two groups. Experimental results are expressed as mean \pm S.E.M. A one-way ANOVA with a least significant difference post hoc test was used to compare mean values between multiple groups, and a two-tailed, unpaired Student's t-test was used for two-group comparisons. In all instances, $P<0.05$ were considered significant. Statistical analyses were performed using SPSS Statistics 22.0 for Macintosh (IBM, Madrid, Spain).

\section{Conflict of Interest}

The authors declare no conflict of interest.

Acknowledgements. This work was funded by The Instituto de Salud Carlos III Grants Pl12/00685, Pl15/00473 and RD12/0014/0007 (to AA), RD12/0014/0001 (to JC), Pl14/01879 and CP12/03121 (to TS), RD12/0043/0021 (to JPB), CD11/00348 (to CR), CD12/00685 (to JA), CM11/00140 (to JJD), CM14/00096 (to MER-A), The Ministerio de Economía y Competitividad Grant SAF2013-41177-R (JPB), The Junta de Castilla y León (GRS843/A/13 and GRS1004/A/14; to JCG-S), The Xunta de Galicia (GRC2014/027; to JC) and the European Regional 
Development Fund (ERDF). We thank all the patients who took part in this study. We also thank Prof. DG Johnson for the generous supply of the humanized Tp53 Arg72Pro KI mouse models. We are grateful to M Carabias, S González, $\mathrm{C}$ Castro and M Resch for technical support.

1. Qureshi Al, Mendelow AD, Hanley DF. Intracerebral haemorrhage. Lancet 2009; 373: 1632-1644.

2. Senn R, Elkind MS, Montaner J, Christ-Crain M, Katan M. Potential role of blood biomarkers in the management of nontraumatic intracerebral hemorrhage. Cerebrovasc Dis 2014; 38: 395-409.

3. Godoy DA, Pinero GR, Koller P, Masotti L, Di Napoli M. Steps to consider in the approach and management of critically ill patient with spontaneous intracerebral hemorrhage. World $\mathrm{J}$. Crit Care Med 2015; 4: 213-229.

4. Small SL, Buccino G, Solodkin A. Brain repair after stroke - a novel neurological model. Nat Rev Neurol 2013; 9: 698-707.

5. Tovar-Y-Romo LB, Penagos-Puig A, Ramirez-Jarquin JO. Endogenous recovery after brain damage: molecular mechanisms that balance neuronal life/death fate. J Neurochem 2016; 136: 13-27.

6. Greenberg DA, Jin K. From angiogenesis to neuropathology. Nature 2005; 438: 954-959.

7. Quaegebeur A, Lange $C$, Carmeliet $P$. The neurovascular link in health and disease: molecular mechanisms and therapeutic implications. Neuron 2011; 71: 406-424.

8. Potente M, Gerhardt H, Carmeliet P. Basic and therapeutic aspects of angiogenesis. Cell 2011; 146: 873-887.

9. Ergul A, Alhusban A, Fagan SC. Angiogenesis: a harmonized target for recovery after stroke. Stroke 2012; 43: 2270-2274

10. Krupinski J, Kaluza J, Kumar P, Kumar S, Wang JM. Role of angiogenesis in patients with cerebral ischemic stroke. Stroke 1994; 25: 1794-1798.

11. Asahara T, Murohara T, Sullivan A, Silver M, van der Zee R, Li T et al. Isolation of putative progenitor endothelial cells for angiogenesis. Science 1997; 275: 964-967.

12. Asahara T, Takahashi T, Masuda $\mathrm{H}, \mathrm{Kalka} \mathrm{C}$, Chen $\mathrm{D}$, Iwaguro $\mathrm{H}$ et al. VEGF contributes to postnatal neovascularization by mobilizing bone marrow-derived endothelial progenitor cells. EMBO J 1999; 18: 3964-3972.

13. Zhang ZG, Zhang L, Jiang Q, Chopp M. Bone marrow-derived endothelial progenitor cells participate in cerebral neovascularization after focal cerebral ischemia in the adult mouse. Circ Res 2002; 90: 284-288.

14. Taguchi A, Soma T, Tanaka H, Kanda T, Nishimura H, Yoshikawa $\mathrm{H}$ et al. Administration of CD34+ cells after stroke enhances neurogenesis via angiogenesis in a mouse model. $J$ Clin Invest 2004: 114: 330-338.

15. Sobrino T, Hurtado O, Moro MA, Rodriguez-Yanez M, Castellanos M, Brea D et al. The increase of circulating endothelial progenitor cells after acute ischemic stroke is associated with good outcome. Stroke 2007; 38: 2759-2764.

16. Yip HK, Chang LT, Chang WN, Lu CH, Liou CW, Lan MY et al. Level and value of circulating endothelial progenitor cells in patients after acute ischemic stroke. Stroke 2008; 39: 69-74.

17. Bogoslovsky T, Chaudhry A, Latour L, Maric D, Luby M, Spatz M et al. Endothelial progenitor cells correlate with lesion volume and growth in acute stroke. Neurology 2010; 75 : 2059-2062.

18. Sobrino T, Arias S, Perez-Mato M, Agulla J, Brea D, Rodriguez-Yanez M et al. Cd34+ progenitor cells likely are involved in the good functional recovery after intracerebral hemorrhage in humans. J Neurosci Res 2011; 89: 979-985.

19. Marin MC, Jost CA, Brooks LA, Irwin MS, O'Nions J, Tidy JA et al. A common polymorphism acts as an intragenic modifier of mutant p53 behaviour. Nat Genet 2000; 25: 47-54.

20. Dumont P, Leu Jl, Della Pietra AC 3rd, George DL, Murphy M. The codon 72 polymorphic variants of p53 have markedly different apoptotic potential. Nat Genet 2003; 33: 357-365.

21. Bonafe M, Salvioli S, Barbi C, Trapassi C, Tocco F, Storci G et al. The different apoptotic potential of the p53 codon 72 alleles increases with age and modulates in vivo ischaemiainduced cell death. Cell Death Diff 2004; 11: 962-973.

22. Pietsch EC, Humbey O, Murphy ME. Polymorphisms in the p53 pathway. Oncogene 2006; 25: 1602-1611.

23. Gomez-Sanchez JC, Delgado-Esteban M, Rodriguez-Hernandez I, Sobrino T, Perez de la Ossa N, Reverte $\mathrm{S}$ et al. The human Tp53 Arg72Pro polymorphism explains different functional prognosis in stroke. J Exp Med 2011; 208: 429-437.

24. Banks JL, Marotta CA. Outcomes validity and reliability of the modified Rankin scale: implications for stroke clinical trials: a literature review and synthesis. Stroke 2007; 38: 1091-1096.

25. Griese DP, Ehsan A, Melo LG, Kong D, Zhang L, Mann MJ et al. Isolation and transplantation of autologous circulating endothelial cells into denuded vessels and prosthetic grafts: implications for cell-based vascular therapy. Circulation 2003; 108: 2710-2715.
26. Hattori K, Dias S, Heissig B, Hackett NR, Lyden D, Tateno M et al. Vascular endothelial growth factor and angiopoietin-1 stimulate postnatal hematopoiesis by recruitment of vasculogenic and hematopoietic stem cells. J Exp Med 2001; 193: 1005-1014.

27. Bogoslovsky T, Spatz M, Chaudhry A, Maric D, Luby M, Frank J et al. Stromal-derived factor1[alpha] correlates with circulating endothelial progenitor cells and with acute lesion volume in stroke patients. Stroke 2011; 42: 618-625.

28. Zhu F, Dolle ME, Berton TR, Kuiper RV, Capps C, Espejo A et al. Mouse models for the p53 R72P polymorphism mimic human phenotypes. Cancer Res 2010; 70: 5851-5859.

29. Clark W, Gunion-Rinker L, Lessov N, Hazel K. Citicoline treatment for experimental intracerebral hemorrhage in mice. Stroke 1998; 29: 2136-2140.

30. Lee HJ, Kim KS, Kim EJ, Choi HB, Lee KH, Park $\mathbb{H}$ et al. Brain transplantation of immortalized human neural stem cells promotes functional recovery in mouse intracerebral hemorrhage stroke model. Stem Cells 2007; 25: 1204-1212.

31. Brooks SP, Dunnett SB. Tests to assess motor phenotype in mice: a user's guide. Nat Rev Neurosci 2009; 10: 519-529.

32. Rafii S, Lyden D. Therapeutic stem and progenitor cell transplantation for organ vascularization and regeneration. Nat Med 2003; 9: 702-712.

33. Case J, Mead LE, Bessler WK, Prater D, White HA, Saadatzadeh MR et al. Human CD34 +AC133+VEGFR-2+ cells are not endothelial progenitor cells but distinct, primitive hematopoietic progenitors. Exp Hematol 2007; 35: 1109-1118.

34. Walchli T, Mateos JM, Weinman O, Babic D, Regli L, Hoerstrup SP et al. Quantitative assessment of angiogenesis, perfused blood vessels and endothelial tip cells in the postnatal mouse brain. Nat Protoc 2015; 10: 53-74.

35. Yu SW, Friedman B, Cheng Q, Lyden PD. Stroke-evoked angiogenesis results in a transient population of microvessels. J Cereb Blood Flow Metab 2007; 27: 755-763.

36. Ritter MR, Banin E, Moreno SK, Aguilar E, Dorrell MI, Friedlander M. Myeloid progenitors differentiate into microglia and promote vascular repair in a model of ischemic retinopathy. $J$ Clin Invest 2006; 116: 3266-3276.

37. Moskowitz MA, Lo EH, ladecola C. The science of stroke: mechanisms in search of treatments. Neuron 2010; 67: 181-198.

38. Xing C, Hayakawa K, Lok J, Arai K, Lo EH. Injury and repair in the neurovascular unit. Neurol Res 2012; 34: 325-330.

39. Urbich C, Aicher A, Heeschen C, Dernbach E, Hofmann WK, Zeiher AM et al. Soluble factors released by endothelial progenitor cells promote migration of endothelial cells and cardiac resident progenitor cells. J Mol Cell Cardiol 2005; 39: 733-742.

40. Rodriguez-Yanez M, Castellanos M, Freijo MM, Lopez Fernandez JC, Marti-Fabregas J, Nombela $\mathrm{F}$ et al. Clinical practice guidelines in intracerebral haemorrhage. Neurologia 2013; 28: 236-249.

41. Broderick J, Connolly S, Feldmann E, Hanley D, Kase C, Krieger D et al. Guidelines for the management of spontaneous intracerebral hemorrhage in adults: 2007 update: a guideline from the American Heart Association/American Stroke Association Stroke Council, High Blood Pressure Research Council, and the Quality of Care and Outcomes in Research Interdisciplinary Working Group. Stroke 2007; 38: 2001-2023.

42. Quintana-Cabrera R, Fernandez-Fernandez S, Bobo-Jimenez V, Escobar J, Sastre J, Almeida $\mathrm{A}$ et al. Gamma-glutamylcysteine detoxifies reactive oxygen species by acting as glutathione peroxidase-1 cofactor. Nat Commun 2012; 3: 718.

43. Almeida A, Bolanos JP, Moreno S.. Cdh1/Hct1-APC is essential for the survival of postmitotic neurons. J Neurosci 2005; 25: 8115-8121.

44. Andjelkovic AV, Stamatovic SM, Keep RF. The protective effects of preconditioning on cerebral endothelial cells in vitro. J Cereb Blood Flow Metab 2003; 23: 1348-1355.

45. Almeida A, Delgado-Esteban M, Bolaños JP, Medina JM. Oxygen and glucose deprivation induces mitochondrial dysfunction and oxidative stress in neurones but not in astrocytes in primary culture. J Neurochem 2002; 81: 207-217.

This work is licensed under a Creative Commons Attribution-NonCommercial-NoDerivs 4.0 International License. The images or other third party material in this article are included in the article's Creative Commons license, unless indicated otherwise in the credit line; if the material is not included under the Creative Commons license, users will need to obtain permission from the license holder to reproduce the material. To view a copy of this license, visit http://creativecommons.org/licenses/by-nc-nd/4.0/

(C) The Author(s) 2017 